\title{
Synthesis and Surface Modification of Spindle-Type Magnetic Nanoparticles: Gold Coating and PEG Functionalization
}

\author{
Juan Mendez-Garza ${ }^{1}$, Biran Wang ${ }^{1}$, Alexandra Madeira ${ }^{1}$, Christophe Di Giorgio ${ }^{2}$, Georges Bossis ${ }^{1}$ \\ ${ }^{1}$ Laboratoire de Physique de la Matière Condensée, UMR 7336, Université de Nice-Sophia Antipolis, CNRS, Parc Valrose, Nice, \\ France; ${ }^{2}$ Institut de Chimie de Nice, UMR 7272, Université de Nice-Sophia Antipolis, CNRS, Parc Valrose, Nice, France. \\ Email: georges.bossis@unice.fr, jmendez@unice.fr
}

Received April $8^{\text {th }}, 2013$; revised May 26 ${ }^{\text {th }}, 2013$; accepted June $10^{\text {th }}, 2013$

Copyright (C) 2013 Juan Mendez-Garza et al. This is an open access article distributed under the Creative Commons Attribution License, which permits unrestricted use, distribution, and reproduction in any medium, provided the original work is properly cited.

\begin{abstract}
In this paper, we describe the synthesis of gold coated spindle-type iron nanoparticles and its surface modification by a thiolated fluorescently-labelled polyethylene glycol (PEG) polymer. A forced hydrolysis of ferric salts in the presence of phosphate ions was used to produce $\alpha-\mathrm{Fe}_{2} \mathrm{O}_{3}$ spindle-type particles. The oxide powders were first reduced to $\alpha$-iron under high temperature and controlled dihydrogen atmosphere. Then, the resulting magnetic spindle-type particles were covered by a shell of gold. The formation of the core@shell structure was driven by a redox-transmetalation reaction between iron(0) at the surface of particles and a gold(III) salt. Protected against oxidation, the Fe@Au core@shell nanoparticles were then grafted with a water soluble fluorescent-PEG-thiol. TEM, XRD, EDX and measurements of magnetic properties of particles confirm 1) the conversion of hematite into iron and 2) their subsequent surface protection with a gold shell. Furthermore, the functionalization of the gold nanoparticle surface with a PEG carrying a fluorescent dye was unambiguously attested by confocal laser scanning microscopy.
\end{abstract}

Keywords: Core@shell; Spindle-Type; Hematite; Magnetic Particles; Gold Coating; Fluorescent-PEG

\section{Introduction}

Over the last decade, many reports have been devoted to the development of new generations of ferric oxide colloids and magnetic nanoparticles, these nano-objects have very attractive properties, which has resulted in a strong demand on several domains as microelectronics, catalysis, water treatment, including applications as MRItraceable drug carriers, cancer cell inhibitors or tumor cell magnetolysis agents $[1,2]$. In particular, special attention has been paid to the formulation of nanoparticles with controlled morphology and narrow size distributions. In the case of hematite $\left(\alpha-\mathrm{Fe}_{2} \mathrm{O}_{3}\right)$, one-dimensional nanostructures with different morphologies such as wire-like, rod-like and belt-like or two-dimensional spherical, elongated (spindle), micro-ring, or pseudo-cubic ones have been elaborated. They are produced by forced hydrolysis of ferric salts. In general, the growth of monocristalline $\alpha-\mathrm{Fe}_{2} \mathrm{O}_{3}$ takes from a few days using hydrothermal techniques to one week under forced hydrolysis at $100^{\circ} \mathrm{C}$ [3]. The anisotropic growth of hematite is generally con- trolled by the presence of different anions like phosphates, sulfates, oxalates or hydroxide ions [4-6]. Hematite is also used as a raw material to produce metallic iron with high magnetic properties. The reduction of $\alpha-\mathrm{Fe}_{2} \mathrm{O}_{3}$ to $\alpha-\mathrm{Fe}(0)$ takes place at roughly $400^{\circ} \mathrm{C}$ under a $\mathrm{H}_{2}$ atmosphere. The main challenge in hematite reduction at high temperature is the aggregation of particles, mainly provoked by the sintering phenomenon that occurs at the interfaces between particles. Furthermore, to prevent uncontrolled re-oxidation of iron, passivation techniques are used. The passivation of metal powders is typically done by growing an oxide layer over the surface of particles, covering its surface with a silica layer or with an inert metallic shell (gold, silver, platinum) creating core@shell structures [7-9]. Passivation of nanoparticles is also required for biocompatibility when in vivo biomedical applications are contemplated.

In this paper, we report the synthesis of spindle-type Fe@Au core@shell nanoparticles (Fe@Au NPs) produced by the reduction of spindle-type hematite nanoparticles and their subsequent gold plating through a trans- 
metalation reaction (Scheme 1). Due to their ellipsoidal morphology and biocompatibility rendered by the gold passivation, magnetic Fe@Au NPs may have a tremendous potential for cancer therapy thanks to tumor cell magnetolysis process $[10,11]$. Aiming at this goal, we have functionalized their surface with polyethylene glycols (PEG), which is an important biocompatible polymer that facilitates the solubilization and long-term circulation of proteins, viruses and other biological macromolecules [12]. We have then functionalized PEGs by substituting both terminal hydroxyl groups with respectively a thiol group (SH) and a fluorescein tag thanks to fluorescein isothiocyanate (FITC), (Scheme 1). The resulting bi-functionalized molecule was grafted to NPs throughout the strong gold-thiol covalent bond and consequently the fluorescein tag gave to particles an optical contrast that could facilitate observations of treated cells by confocal microscopy in the case of magnetolysis therapy. It is nevertheless important to note that the surface labeling can be easily adapted providing specific targeting of cancer cells by tethering ligands such as folic acid, RGD peptides or growth factor (e.g. VEGF) ligands at the PEG extremity in place of the fluorescent dye. Although spindle-type Fe@Au nanoparticles have already been described, the displacement reaction of iron by gold without the need of any additional agent, i.e. reducing agents or microemulsion became an interesting option for the preparation of spindle-type Fe@Au core@shell nanoparticles [13-15].

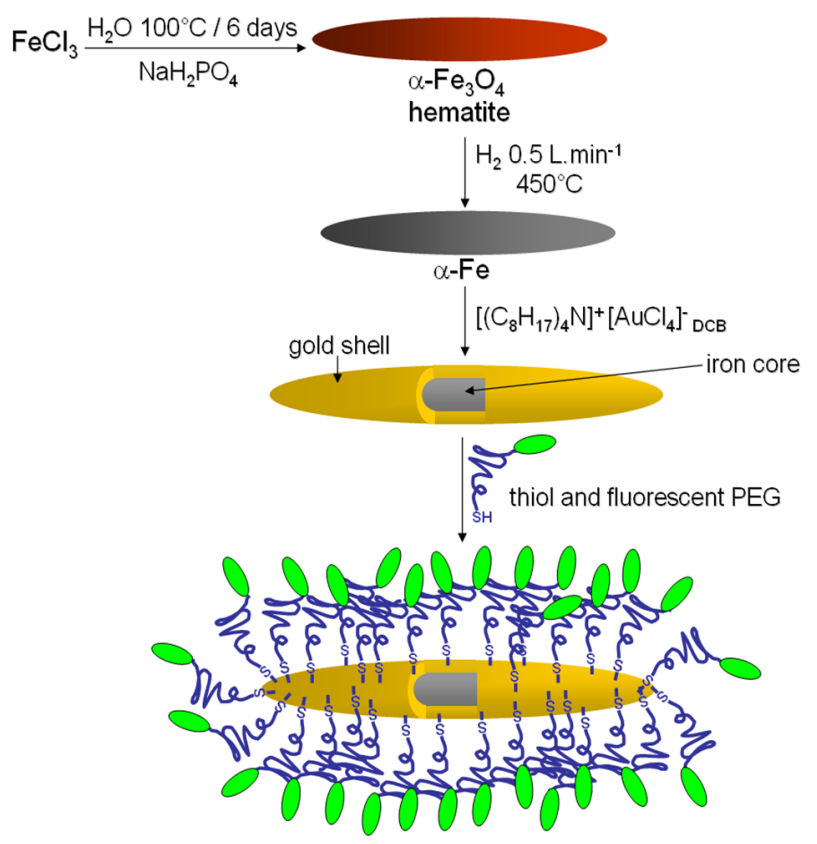

Scheme 1. General procedure to obtain the pegylated iron@gold (core@shell) NPs.

\section{Experimental Section}

\subsection{Chemicals}

Reactions were carried out under inert atmosphere using appropriate techniques. Iron(III) chloride hexahydrate $\left(\mathrm{FeCl}_{3} \cdot 6 \mathrm{H}_{2} \mathrm{O}\right)$, trichloroethylene $\left(\mathrm{C}_{2} \mathrm{HCl}_{3}\right), 1,2$ dichlorobenzene (DCB), tetraoctylammonium bromide (TOAB) $\left[\mathrm{C}_{8} \mathrm{H}_{17}\right]_{4} \mathrm{~N}^{+} \mathrm{Br}^{-}$, and auric acid $\left(\mathrm{HAuCl}_{4}\right)$ were supplied by Sigma-Aldrich. $\mathrm{H}_{2} \mathrm{~N}-\mathrm{PEG}_{5000}-\mathrm{STrt}(\alpha$-amino- $\omega$-tritylthio-poly(ethylene glycol) $\mathrm{Mw}=5000$ Dalton) was supplied by IRIS Biotech GMBH. Sodium phosphate monobasic $\left(\mathrm{NaH}_{2} \mathrm{PO}_{4}\right)$ was supplied by Fluka. Ultra pure water $18.2 \mathrm{M} \Omega \mathrm{cm}$ was obtained from a Thermo Scientific water purification device.

\subsection{Characterization Techniques}

The polyethylene glycol was verified by nuclear magnetic resonance $\left({ }^{1} \mathrm{H}\right.$ NMR, Bruker AC-200 MHz spectrometer). Structure and properties of iron and hematite were studied by X-ray diffractions (XRD, Bracket PW307) at $45 \mathrm{kV}$ and $30 \mathrm{~mA}$. The instrument used a Cu $\mathrm{K} \alpha$ radiation with a wavelength of $1.54060 \AA$, samples were placed in a glass holder and were scanned from 6 to $110^{\circ}, 2 \theta$ ), transmission electron microscopy (TEM, JEOL JEM-1400), scanning electron microscopy (SEM, FEI XL30 ESEM LaB6) coupled to an energy dispersive analyzer (EDX, EDX Oxford/INCA). Surface modification of particles with the fluorescent polymers was analyzed with a Leica SPE confocal microscope using a $63 \times 1.4$ N.A. oil immersion objective. Magnetic properties of samples were investigated using a M2000/2100 hysteresis meter.

\subsection{Synthesis of Hematite Spindle-Type Particles}

The preparation of $\alpha-\mathrm{Fe}_{2} \mathrm{O}_{3}$ particles was performed according to a method, which has been described elsewhere $[4,16]$ and adapted for a larger scale $(5-10 \mathrm{~g})$ synthesis. Briefly, $5.41 \mathrm{~g}(0.02 \mathrm{M})$ of $\mathrm{FeCl}_{3} \cdot 6 \mathrm{H}_{2} \mathrm{O}$ and $0.054 \mathrm{~g}(0.45$ $\mathrm{mM}$ ) of $\mathrm{NaH}_{2} \mathrm{PO}_{4}$ were dissolved in $1 \mathrm{~L}$ of ultra pure water and kept undisturbed during 6 days at $100^{\circ} \mathrm{C}$. Then, a filtration method to wash off sub-products (mainly salts) of hematite suspensions was applied.

The filtration system allowed particles to be continuously washed without drying or concentrating particles. The filtration system was composed by a ceramic hollow membrane coupled with a steel membrane housing. The suspension of particles was injected into this system, washed with ultra pure water until the suspension resistivity reached around $18 \mathrm{M} \Omega \mathrm{cm}$ at room temperature and finally freeze-dried. This filtration method, combined to freeze-drying procedure, prevented hematite from agglomeration and ensured the full dispersion of lyophilized nanoparticles. 


\subsection{Hematite Reduction to Iron(0)}

The non-agglomerated hematite powders (10 g) obtained above was calcinated in a modified furnace chamber at $450^{\circ} \mathrm{C}$ under a continuous $\mathrm{H}_{2}$ flow $\left(0.5 \mathrm{~L} \mathrm{~min}^{-1}\right)$ during 4 h. The temperature was controlled by a PID-controller included in the tube furnace (Pirox). The vertical tube furnace was modified to introduce a vertical column support adapted to spread $\mathrm{H}_{2}$ through the sample (Scheme 2). The home-made column support came from a modified Pirex buchner filter funnel lengthen in bottom. The colu$\mathrm{mn}$ incorporated a sintered silica distributor in bottom, and a quartz wool was placed on top to prevent the fluidized powder to escape from the column.

The whole particles turned from reddish to black indicating conversion of $\mathrm{Fe}(\mathrm{III})$ into $\mathrm{Fe}(0)$. After cooling under a $\mathrm{N}_{2}$ stream, the column was pulled down and trichloroethylene $(20 \mathrm{~mL})$ was added under $\mathrm{N}_{2}$ flow to avoid oxidation of the resulting $\alpha-\mathrm{Fe}(0) \mathrm{NPs}$, which were kept into this solvent for further experiments. Very interestingly, it should be mentioned that no sintering was observed during this step.

\subsection{Surface Modification of Iron Particles}

Synthesis of FITC-PEG $\mathbf{5 0 0 0}_{\mathbf{5 0}}$-SH. $\mathrm{H}_{2} \mathrm{~N}-\mathrm{PEG}_{5000}-\mathrm{STrt}(250$ $\mathrm{mg}, 0.05 \mathrm{mmol})$ was dissolved into $\mathrm{CH}_{2} \mathrm{Cl}_{2} / \mathrm{DMF}(5 / 1$, $\mathrm{v} / \mathrm{v}) 600 \mu \mathrm{L}$ and then FITC $(19.5 \mathrm{mg}, 0.25 \mathrm{mmol})$ and $\mathrm{Et}_{3} \mathrm{~N}(50 \mu \mathrm{L}, 0.5 \mathrm{mmol})$ were added. The mixture was stirred overnight and diethyl ether was then added. The precipitated was filtered off, washed with ether and then dried over vacuo. S-Trityl protecting group was then removed with TFA to lead, after precipitation with diethyl ether, the desired thiol, Fluorescein- $\mathrm{PEG}_{5000}-\mathrm{SH}$ with $90 \%$ overall yield as a yellow-orange solid.

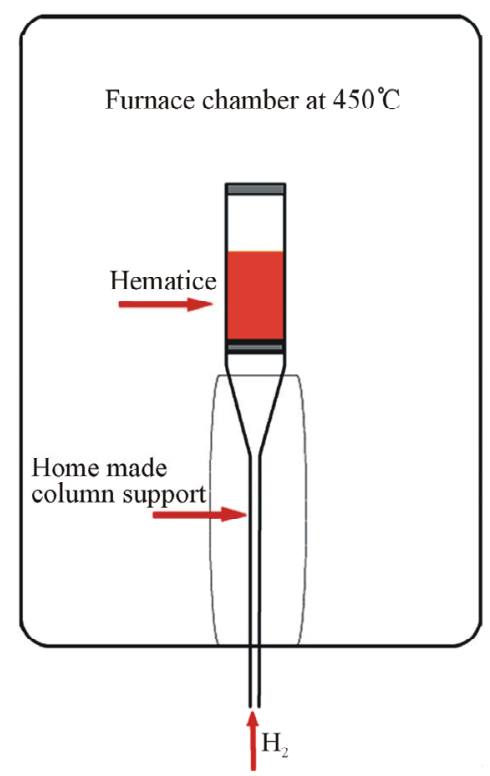

Scheme 2. Furnace scheme of $\alpha-\mathrm{Fe}_{2} \mathrm{O}_{3}$ powders reduction.
NMR analysis of PEG. NMR ${ }^{1} \mathrm{H}\left(\delta\right.$ ppm, $\mathrm{D}_{2} \mathrm{O}, 200$ $\mathrm{MHz}): 2.3$ - 2.65 (m, $\left.4 \mathrm{H}, \mathrm{CH}_{2} \mathrm{SH}, \mathrm{CH}_{2} \mathrm{CONH}\right), 3.11$ $3.38\left(\mathrm{~m},\left(\mathrm{CH}_{2} \mathrm{O}, \mathrm{CH}_{2} \mathrm{NH}, 310 \mathrm{H}\right], 6.43-6.63(\mathrm{~m}, 6 \mathrm{H}, \mathrm{H}\right.$ aromatic FITC), 7.02 (d, $1 \mathrm{H}, \mathrm{J} 8.1 \mathrm{~Hz}, \mathrm{H}$ aromatic FITC), 7.57 - 7.62 (m, 1 H, H aromatic FITC), 7.80 - 7.83 (m, 2 $\mathrm{H}, \mathrm{H}$ aromatic FITC).

Fe@Au NPs preparation. Gold coating of $\alpha$ - $\mathrm{Fe}(0)$ NPs was adapted and performed according to a described procedure [17]. First, hydrophobized gold(III) salt $\left[\left(\mathrm{C}_{8} \mathrm{H}_{17}\right)_{4} \mathrm{~N}\right]^{+}\left[\mathrm{AuCl}_{4}\right]^{-}$were obtained from a phase transfer after mixing solutions of TOAB in DCB and aqueous $\mathrm{HAuCl}_{4}$ under vigorous stirring. $\left[\left(\mathrm{C}_{8} \mathrm{H}_{17}\right)_{4} \mathrm{~N}\right]^{+}\left[\mathrm{AuCl}_{4}\right]^{-}$ (290 mg, $0.36 \mathrm{mmol}$ ) were dissolved into $20 \mathrm{~mL}$ of DCB and added $100 \mathrm{mg}$ of NPs under $\mathrm{N}_{2}$ atmosphere, the mixture were then heated at $90^{\circ} \mathrm{C}$ for $2 \mathrm{~h}$ while kept under inert atmosphere and maintained under mechanical stirring. The reaction was quenched by adding $40 \mathrm{~mL}$ of absolute ethanol (EtOH). Fe@Au NPs were subjected to centrifugation/washing cycles with absolute $\mathrm{EtOH}$ (five times). Finally, particles were suspended into absolute $\mathrm{EtOH}$ and kept under a $\mathrm{N}_{2}$ atmosphere for further experiments.

Surface modification of Fe@Au NPs. $500 \mu \mathrm{L}$ of the Fe@Au NPs stock suspension $\left(10 \mathrm{mg} \cdot \mathrm{mL}^{-1}\right.$ in absolute EtOH) were degassed. Then, $500 \mu \mathrm{L}$ of freshly made fluorescein- $\mathrm{PEG}_{5000}-\mathrm{SH}$ stock solution $(10 \mathrm{mM}$ in ultra pure water), which was previously degassed and filtered $(0.22$ $\mu \mathrm{m}$, cellulose acetate), was added under $\mathrm{N}_{2}$. The resulting mixture was then stirred for $2 \mathrm{~h}$ under $\mathrm{N}_{2}$. Pegylated Fe@Au NPs were purified by several centrifugation/resuspension cycles into ultra pure water until the fluorescence signal of discarded water reached background level. Finally, FITC-PEG 5000 -labelled Fe@Au NPs were suspended into ultra pure water $(1 \mathrm{~mL})$ and further analyzed by TEM and confocal microscope to evidence functionalization.

\section{Results and Discussion}

\subsection{Morphology and Structure of Hematite and Iron NPs}

$\alpha-\mathrm{Fe}_{2} \mathrm{O}_{3}$ and $\alpha-\mathrm{Fe}(0)$ NPs resulting from the reduction process were analyzed by TEM and X-ray spectroscopy. The morphology and dimensions of particles were evaluated throughout a series of TEM pictures counting approximately 200 particles. Figure 1 displays a typical single particle of $\alpha-\mathrm{Fe}_{2} \mathrm{O}_{3}$ (A) and $\alpha-\mathrm{Fe}(0)$ NPs (B). It is important to mention that the shape of particles kept undisturbed during the whole process of reduction of the oxide into a metal phase. The average sizes measured from the TEM pictures were $580( \pm 50) \mathrm{nm}$ in length and of $80( \pm 5) \mathrm{nm}$ in width.

Figure 1 presents also the XRD patterns of both hematite and iron. X-ray pattern (a) exhibits crystal planes 


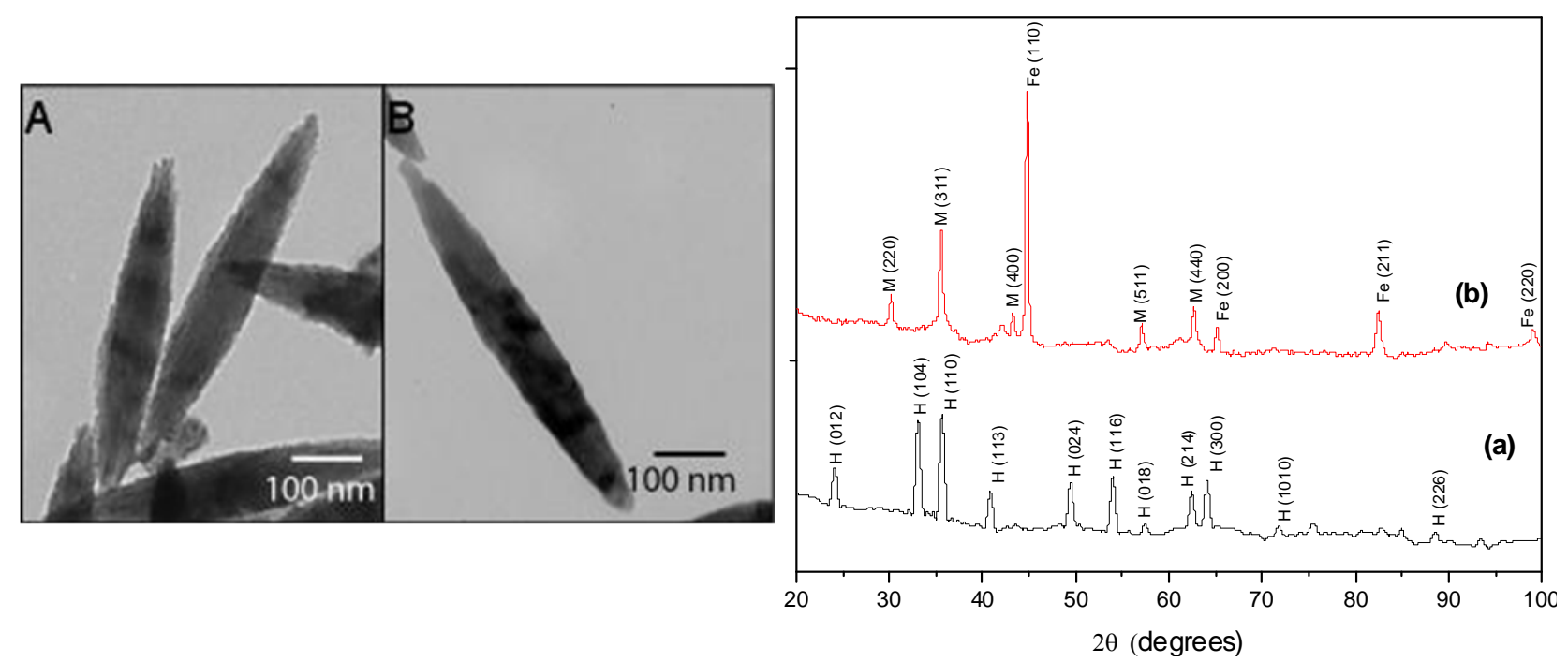

Figure 1. TEM pictures of (A) $\alpha$-Fe $\mathrm{O}_{3}$ and (B) $\alpha$-Fe(0) NPs. X-ray diffraction patterns of $\alpha-\mathrm{Fe}_{2} \mathrm{O}_{3}$ (a) and $\alpha$-Fe(0) NPs (b), where planar peaks are hematite $(\mathrm{H})$, iron $(\mathrm{Fe})$ and magnetite $(\mathrm{M})$.

corresponding only to Hematite. Pattern (b) shows two main phases, iron and magnetite. In (b), the crystallite sizes were estimated using the Scherrer equation with the characteristic reflections corresponding to iron (110) and magnetite (311), and were evaluated to 23 and $20 \mathrm{~nm}$ respectively. [18] Further magnetization measurements (see Section 3.4) are conjugated to these values to quantify the magnetic part of particles.

\subsection{Fe@Au NPs Structure}

Figure 2 shows the X-ray diffraction pattern of $\mathrm{Fe} @ \mathrm{Au}$ NPs. In this spectrum we have observed the characteristic peaks of iron, gold and magnetite, iron and gold peaks are overlapped at the diffractions peaks of $2 \theta=43.2^{\circ}$, $62.7^{\circ}$ and $82.43^{\circ}$. Single peaks of gold and iron at $77.7^{\circ}$ and $98.8^{\circ}$ are respectively detected. It is as well observed the presence of magnetite as seen in Figure 1 (b). The core-shell structures of iron and gold were also corrobarated by SEM-EDX microscopy, Figure 3 presents the microanalysis of NPs presented in the inset of Figure 3. The EDX spectrum exhibits peaks for $\mathrm{Fe}, \mathrm{O}, \mathrm{P}$ and $\mathrm{Au}$. The presence of Phosphorus is due to the phosphate introduction during the synthesis of hematite, the weak gold signal is due to the thin gold coating shell (see next section). These studies carried out by and XRD and SEM-EDX illustrate the coating of Fe@Au NPs and demonstrate that the presence of magnetite does not disturb the smooth reaction process, where a shell layer formation and core metal consumption occur simultaneously between surface $\mathrm{Fe}$ atoms of $\alpha-\mathrm{Fe}(0) \mathrm{NPs}$ and $\mathrm{Au}(\mathrm{III})$ ions of $\left[\left(\mathrm{C}_{8} \mathrm{H}_{17}\right)_{4} \mathrm{~N}\right]^{+}\left[\mathrm{AuCl}_{4}\right]^{-}$in a non aqueous solvent.

\subsection{Magnetic Properties of Fe and Fe@Au NPs}

Powders of spindle-type Fe and Fe@Au NPs were analy-

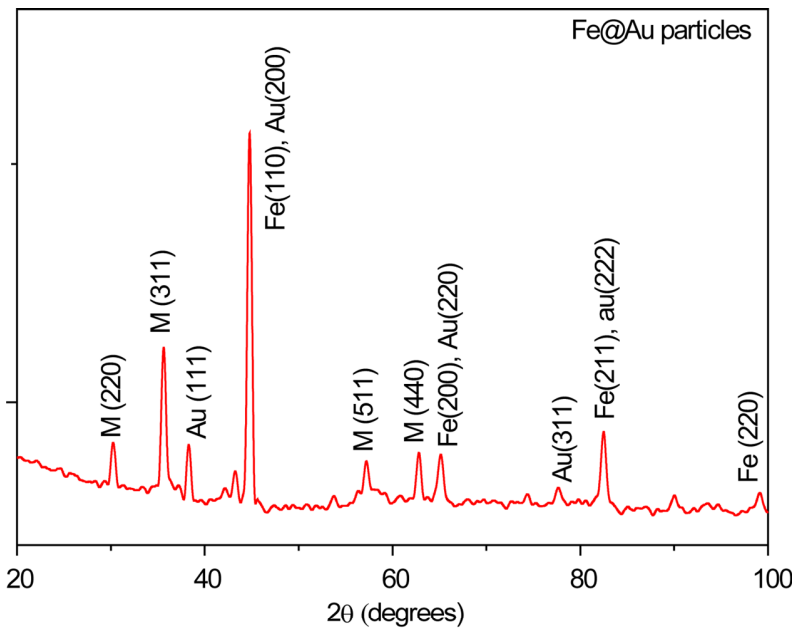

Figure 2. X-ray diffraction patterns of Fe@Au, where planar peaks are iron (Fe), gold (Au) and magnetite (M).

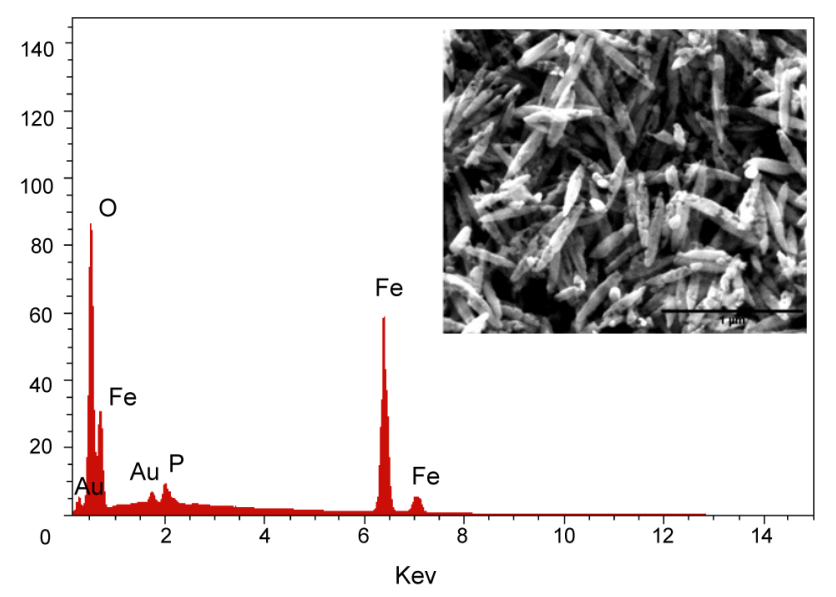

Figure 3. EDX spectrum of Fe@Au NPs, inset SEM image of Fe@Au NPs. 
zed by magnetization hysteresis loops at room temperature (Figure 4) and Table 1 presents the results determined from these curves: saturation magnetization $\left(\mathrm{M}_{\mathrm{s}}\right)$, remanent magnetization $\left(\mathrm{M}_{\mathrm{r}}\right)$, coercivity $\left(\mathrm{H}_{\mathrm{c}}\right)$ and squareness ratio $\left(\mathrm{S}_{\mathrm{r}}=\mathrm{M}_{\mathrm{r}} / \mathrm{M}_{\mathrm{s}}\right)$.

The ferromagnetic nature of the nanoparticles is characterized by the ratio of remanence to saturation magnetization $\left(\mathrm{S}_{\mathrm{r}}\right)$. Particular attention has been paid to the saturation magnetization $\left(\mathrm{M}_{\mathrm{s}}\right)$ parameter, which is defined as the maximum of the magnetization value achieved in a sufficient large magnetic field. Table 1 shows that the saturation magnetization of gold-coated Fe@Au NPs $\left(\mathrm{M}_{\mathrm{s}}^{\mathrm{Fe} @ \mathrm{Au}}\right)$ is lower than the value determined for noncoated $\alpha$-Fe NPs powders $\left(\mathrm{M}_{\mathrm{s}}^{\mathrm{Fe}}\right)$, as expected owing to the non magnetic gold shell constituting the Fe@Au NPs. However, both these $\mathrm{M}_{\mathrm{s}}^{\mathrm{Fe}}$ and $\mathrm{M}_{\mathrm{s}}^{\mathrm{Fe} @ A u}$ values are lower than the $M_{s}$ value reported in the literature for bulk iron $\left(\mathrm{M}_{\mathrm{s}}^{\mathrm{bulk}}=222 \mathrm{emu} \cdot \mathrm{g}^{-1}\right)$ [19]. These differences are most likely related to the presence of the residual oxide phase detected by XRD and EDX. Nevertheless these values of $\mathrm{M}_{\mathrm{s}}$ are similar to those reported in literature for similar spindle-type iron nanoparticles [4].

\subsection{Magnetic Part and Gold Shell Thickness Quantification on NPs}

Using the $\mathrm{M}_{\mathrm{s}}$ values, one can calculate the magnetic and non magnetic part in single magnetic NPs and consequently deduce the thickness of the gold shell on the

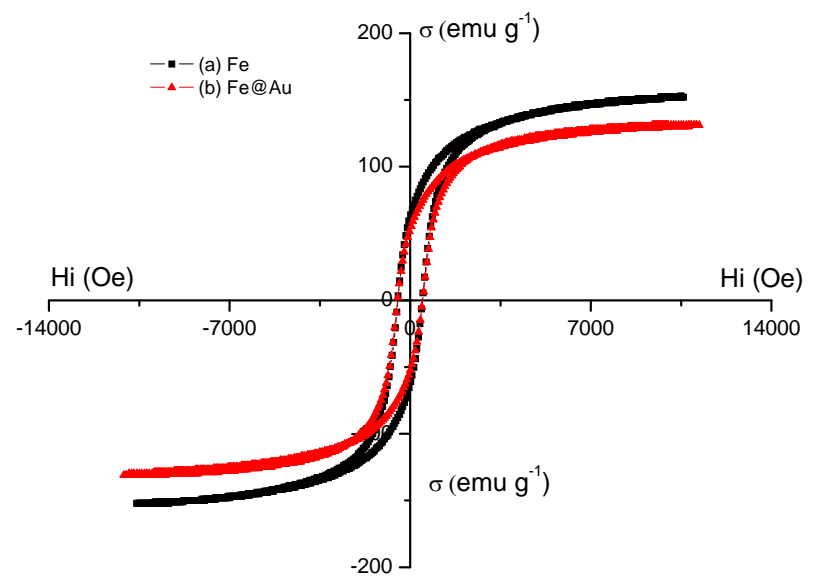

Figure 4. Hysteresis loops of (a) $\alpha$-Fe and (b) Fe@Au NPs.

Table 1. Magnetic properties of Fe and Fe@Au NPs determined from hysteresis loops.

\begin{tabular}{ccccc}
\hline & $\mathrm{H}_{\mathrm{c}}(\mathrm{Oe})$ & $\mathrm{M}_{\mathrm{s}}\left(\mathrm{emu} \cdot \mathrm{g}^{-1}\right)$ & $\mathrm{M}_{\mathrm{r}}\left(\mathrm{emu} \cdot \mathrm{g}^{-1}\right)$ & $\mathrm{S}_{\mathrm{r}}$ \\
\hline Fe NPs & 294 & 156 & 34.9 & 0.224 \\
$\mathrm{Fe} @ \mathrm{Au} \mathrm{NPs}$ & 485 & 131 & 52.6 & 0.401 \\
\hline
\end{tabular}

Fe@Au NPs. The magnetic moment $(\mu)$ of a particle $(p)$ is given by: $\mu=V_{p} \cdot M_{s}^{p} \cdot \rho_{p}$, where $\mathrm{V}_{\mathrm{p}}$ is the volume of the particle, $\rho_{p}$ its density and $M_{S}^{p}$ its saturation magnetization. Applying this relationship to the bulk iron, one obtains thus the Equation (1):

$$
\frac{V_{b u l k}}{V_{p}}=\frac{\rho_{p} \cdot M_{\mathrm{s}}^{p}}{\rho_{\text {bulk }} \cdot M_{s}^{\text {bulk }}}
$$

Applying this equation to the data measured on the $\alpha$-Fe NPs (Table 1 for the $\mathrm{M}_{\mathrm{s}}$ values) and to the densities found for $\rho_{p}\left(=5.3 \pm 0.1 \mathrm{~g} \cdot \mathrm{cm}^{-3}\right.$, experimenatlly determinated) and $\rho_{\text {bulk }}\left(=7.86 \mathrm{~g} \cdot \mathrm{cm}^{-3},[19]\right)$, one obtains $V_{\text {bulk }}=0.47 \cdot V_{p}$. This indicates that $47 \%$ in volume $(70 \%$ in mass) of the $\alpha$-Fe NPs is magnetic, the other non magnetic part being either voids or the residual phase formed during the reduction of the hematite.

For the calculation of the gold shell thickness $(e)$, covering the Fe@Au NPs, one can assume that $e$ is related to the volume increment $\mathrm{dV} / \mathrm{V}$ of the ellipsoidal particles, which is the total differential (Equation (2)) of the volume of an ellipsoid:

$$
V=4 \pi / 3 \cdot a^{2} b
$$

Assuming that the thickness $e$ of the gold layer is homogeneous in both $a$ and $b$ axes of the ellipsoid ( $\mathrm{d} a=\mathrm{d} b=e$ ), then the thickness of the gold layer is given by:

$$
\mathrm{e}(\mathrm{nm})=\frac{\mathrm{ab}}{2(\mathrm{a}+\mathrm{b})} \cdot \frac{\mathrm{d} V}{V}
$$

$\mathrm{dV} / \mathrm{V}$ is calculated from the magnetization of both Fe (Equation (4)) and Fe@Au NPs (Equation (5)) as follow:

$$
\begin{gathered}
M_{s}^{F e} \propto \frac{N_{F e}}{m_{F e}} \\
M_{s}^{F e @ A u} \propto \frac{N_{F e}^{\prime}}{m_{F e @ A u}}
\end{gathered}
$$

where 1) $M_{s}^{F e}$ and, $M_{s}^{F e @ A u}$ 2) $N_{\mathrm{Fe}}$ and $N_{\mathrm{Fe}}^{\prime}$ and 3) $m_{\mathrm{Fe}}$ and $m_{\mathrm{Fe} @ \mathrm{Au}}$ are the saturation magnetization, the number of Fe atoms, and the mass of one single $\mathrm{Fe}$ and Fe@Au particle, respectively.

Taking into account that the stoechiometry of the $\mathrm{Fe} / \mathrm{Au}$ displacement reaction at the surface of the Fe particle is of $1: 1$ (any single $\mathrm{Fe}(0)$ atom at the surface is oxidized into $\mathrm{Fe}(\mathrm{III})$ and is replaced by a single $\mathrm{Au}(0)$ atom resulting from the reduction of one $\mathrm{Au}(\mathrm{III})$ present in the solution), this indicates that $N_{\mathrm{Fe}}^{\prime}$ becomes equal to $N_{\mathrm{Fe}}-N_{\mathrm{Au}}$, where $N_{\mathrm{Au}}$ is the number of $\mathrm{Au}$ atoms forming the coating of one $\mathrm{Fe} @ \mathrm{Au}$ particle. This exchange reaction, which concerns almost exclusively the first outer layer of Fe atoms in contact with the $\mathrm{Au}(\mathrm{III})$ solution has 
no consequences onto the geometrical parameters $(a, b$ and $\mathrm{V}$ ) of the ellipsoid. Combining Equations (4) and (5) and replacing $N_{\mathrm{Fe}}^{\prime}$ by $N_{\mathrm{Fe}}-N_{\mathrm{Au}}$, one obtains Equation (6):

$$
\frac{N_{A u}}{N_{F e}}=\frac{M_{s}^{F e} / M_{s}^{F e @ A u}-1}{\left(M_{s}^{F e} / M_{s}^{F e @ A u}-1\right)+M_{A u}^{w} / M_{F e}^{w}}
$$

where $M_{\mathrm{wFe}}$ and $M_{\mathrm{wAu}}$ are the molecular weight of iron and gold, respectively.

Applying Equation (6) to the data measured on the $\alpha$-Fe and Fe@Au NPs (Table 1), one obtains the relation: $\frac{d V}{V}=\frac{N_{A u}}{N_{F e}}$ the thickness of gold layer in the Fe@Au NPs was then estimated to be of nearly $1.8 \mathrm{~nm}$.

\subsection{Pegylated Fe@Au NPs Characterization}

By taking advantage of the high Au-S affinity, the gold surface of Fe@Au NPs was stained through chemisorption with FITC-PEG ${ }_{5000}-\mathrm{SH}$. Surface gold staining with fluorescence was attested by confocal microscopy. Figure 5 shows a 3D-picture constructed with ImageJ recorded from a Z-stack of 28 different views (longitudinal sections on the Z-axis) with the green emission mode $\left(\lambda_{\mathrm{em}}=520 \mathrm{~nm}, \lambda_{\mathrm{ex}}=490 \mathrm{~nm}\right)$. It should be noted that an additional red emission mode (with $\lambda_{\mathrm{em}}=620 \mathrm{~nm}, \lambda_{\mathrm{ex}}=$ $590 \mathrm{~nm}$ ) was also tested as negative control (data not shown). This latter, as expected, could not result into any

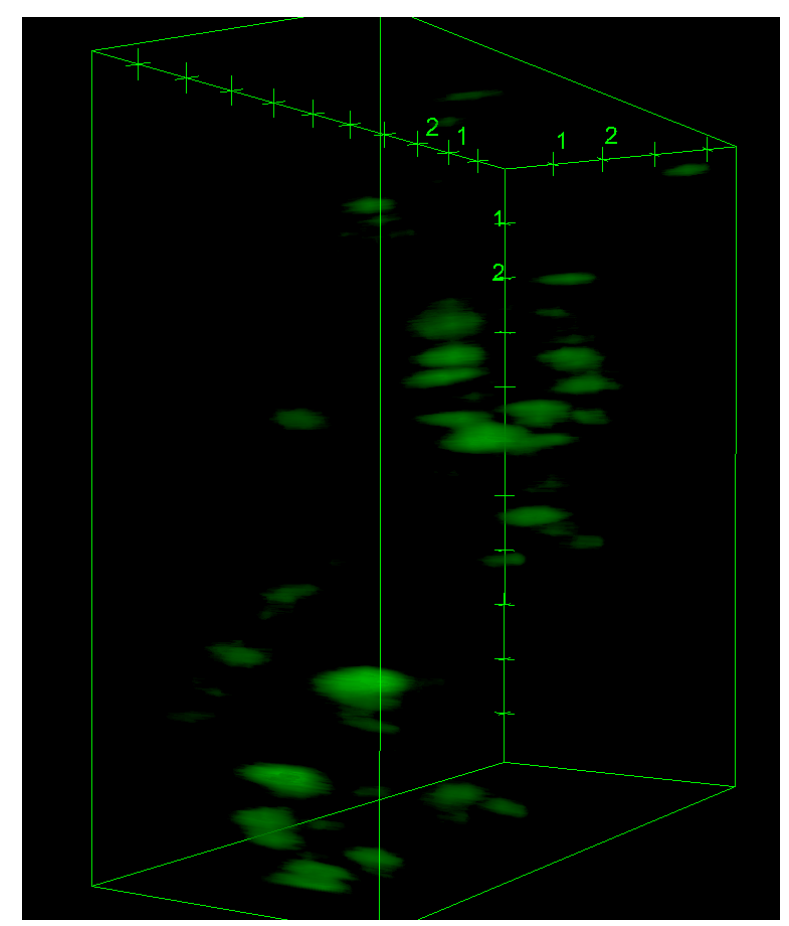

Figure 5. Confocal microscopy 3D-picture of Fe@Au-SPEG $_{5000}$ (FITC) NPs in emission mode (green channel). The bounding box displays xyz coordinate system as well as units (scale in $\mu \mathrm{m}$ ). red light emission. Green staining is only located at the surface of nanoparticles and clearly evidences their acicular shape. This experiment shows that Fe@Au NPs have been functionalized with the FITC-PEG-SH. It indicates also that PEG can provide dispersion of the $\mathrm{Fe} @ \mathrm{Au}$ NPs into aqueous media by creating a steric and hydrophilic shield. This strategy can be applied to functionalize the surface of $\mathrm{Fe} @ \mathrm{Au}$ NPs for specific cell recognition by tethering a suitable ligand at the PEG extremity.

\section{Conclusion}

In this paper, we demonstrated the feasibility to obtain highly disperse spindle-type hematite NPs and to reduce these into acicular metallic iron NPs under a $\mathrm{H}_{2}$ flow at $450^{\circ} \mathrm{C}$ without sintering. By using a redox transmetalation process, the Fe core serves as a nanoelectrode for the spontaneous deposition of gold onto the surface of NPs without the need of any additional agent. From the comparison of the saturation magnetizations, we have determinated that $70 \%(\mathrm{w} / \mathrm{w})$ of particles are magnetic and the thickness of the gold layer was about $1.8 \mathrm{~nm}$. The gold surface of the Fe@Au NPs was also functionalized with stained PEG thiol conjugates that provide dispersion of the Fe@Au NPs into aqueous media. Interestingly, the magnetic properties of Fe@Au NPs were only slightly lowered by the presence of the gold shell when compared to non passivated $\alpha$-Fe NPs. This is important since further developments involving their mechanical action under alternative or rotating magnetic field are required to destabilize cell membrane of targeted cells. Studies in this field are currently in progress to use such $\mathrm{Fe} @ \mathrm{Au}$ NPs for specific cancer cell magnetolysis. This could be set by using PEG-ligand conjugates to selectively target specific receptors that are overexpressed onto cancer cells (VEGF, folate or integrin receptors for example). Other domains such as nanobiosensors or nanocarriers taking advantages of their optic properties are still in development.

\section{Acknowledgements}

The authors gratefully acknowledge S. Pagnotta and J.P. Laugier for the TEM images. Authors thank P. Kuzhir and M. Lopez-Lopez for their comments on the manuscript; B. Wang is indebted to Region PACA and CNRS project BioMag for financial support. We also thank Pr J. Persello for his advices and technical help in the reduction and coating of magnetic particles.

\section{REFERENCES}

[1] Y. N. Wu, D. H. Chen, X. Y. Shi, C. C. Lian, T. Y. Wang, C. S. Yeh, K. R. Ratinac, P. Thordarson, F. Braet and D. B. Shieh, "Cancer-Cell-Specific Cytotoxicity of Non-Oxidized Iron Elements in Iron Core-Gold Shell NPs," $\mathrm{Na}$ nomedicine: Nanotechnology, Biology and Medicine, Vol. 
7, No. 4, 2011, pp. 420-427. doi:10.1016/j.nano.2011.01.002

[2] M. Chen, S. Yamamuro, D. Farrell and S. A. Majetich, "Gold-Coated Iron Nanoparticles for Biomedical Applications," Journal of Applied Physics, Vol. 93, No. 10, 2003, pp. 7551-7553. doi:10.1063/1.1555312

[3] K. Kandori and T. Ishikawa, "Preparation and Microstructural Studies on Hydrothermally Prepared Hematite," Journal of Colloid and Interface Science, Vol. 272, No. 1, 2004, pp. 246-248. doi:10.1016/j.jcis.2003.08.075

[4] T. Ishikawa and E. Matijevic, "Formation of Monodispersed Pure and Coated Spindle-Type Iron Particles," Langmuir, Vol. 4, No. 1, 1988, pp. 26-31. doi:10.1021/la00079a004

[5] M. Ocaña, M. P. Morales and C. J. Serna, "Homogeneous Precipitation of Uniform $\alpha-\mathrm{Fe}_{2} \mathrm{O}_{3}$ Particles from Iron Salts Solutions in the Presence of Urea," Journal of Colloid and Interface Science, Vol. 212, No. 2, 1999, pp. 317-323. doi:10.1006/jis.1998.6042

[6] X. L. Gou, G. X. Wang, J. Park, H. Liu and J. Yang, "Monodisperse Hematite Porous Nanospheres: Synthesis, Characterization, and Applications for Gas Sensors," Nanotechnology, Vol. 19, No. 12, 2008, Article ID: 125606. doi:10.1088/0957-4484/19/12/125606

[7] C. Baker, S. K. Hasanain and S. I. Shah, "The Magnetic Behavior of Iron Oxide Passivated Iron Nanoparticles," Journal of Applied Physics, Vol. 96, No. 11, 2004, pp. 6657-6662. doi:10.1063/1.1806263

[8] E. E. Carpenter, S. Calvin, R. M. Stroud and V. G. Harris, "Passivated Iron as Core-Shell Nanoparticles," Chemical Materials, Vol. 15, No. 17, 2003, pp. 3245-3246. doi:10.1021/cm0341311

[9] K. K. Fung, B. Qin and X. X. Zhang, "Passivation of $\alpha-\mathrm{Fe}$ Nanoparticle by Epitaxial $\gamma$ - $\mathrm{Fe}_{2} \mathrm{O}_{3}$ Shell," Materials Science and Engineering: A, Vol. 286, No. 1, 2000, pp. 135138. doi:10.1016/S0921-5093(00)00717-6

[10] S. H. Hu and X. Gao, "Nanocomposites with Spatially Separated Functionalities for Combined Imaging and Magnetolytic Therapy," Journal of American Chemistry Society, Vol. 132, No. 21, 2010, pp. 7234-7237. doi:10.1021/ja102489q

[11] D. H. Kim, E. A. Rozhkova, I. V. Ulasov, S. D. Bader, T. Rajh, M. S. Lesniak and V. Novosad, "Biofunctionalized Magnetic-Vortex Microdiscs for Targeted Cancer-Cell
Destruction," Natural Materials, Vol. 9, No. 2, 2010, pp. 165-171. doi:10.1038/nmat2591

[12] S. Zalipsky and J. M. Harris, "Introduction to Chemistry and Biological Applications of Poly(Ethylene Glycol), in Poly(Ethylene Glycol)," American Chemical Society, 1997, pp. 1-13. doi:10.1021/bk-1997-0680.ch001

[13] C. Leostean, O. Pana, R. Turcu, M. L. Soran, S. Macavei, O. Chauvet and C. Payen, "Comparative Study of CoreShell Iron/Iron Oxide Gold Covered Magnetic Nanoparticles Obtained in Different Conditions," Journal of Nanoparticle Research, Vol. 13, No. 11, 2011, pp. 6181-6192. doi:10.1007/s11051-011-0313-3

[14] Z. Ma, H. Han, S. Tu and J. Xue, "Fabrication of ShapeControlled Hematite Particles and Growth of Gold Nanoshells," Colloids and Surfaces A: Physicochemical and Engineering Aspects, Vol. 334, No. 1-3, 2009, pp. 142-146. doi:10.1016/j.colsurfa.2008.10.015

[15] H. Salehizadeh, E. Hekmatian, M. Sadeghi and K. Kenne$\mathrm{dy}$, "Synthesis and Characterization of Core-Shell $\mathrm{Fe}_{3} \mathrm{O}_{4}$ Gold-Chitosan Nanostructure," Journal of Nanobiotechnology, Vol. 10, No. 1, 2012, pp. 1-7. doi:10.1186/1477-3155-10-3

[16] M. P. Morales, T. Gonazles-Carreño and C. J. Serna, "The Formation of a- $\mathrm{Fe}_{2} \mathrm{O}_{3}$ Monodispersed Particles in Solution," Journal of Material Research, Vol. 7, 1992, pp. 2538-2545. doi:10.1557/JMR.1992.2538

[17] W. R. Lee, M. G. Kim, J. R. Choi, J. L. Park, S. J. Ko, S. J. Oh and J. Cheon, "Redox-Transmetalation Process as a Generalized Synthetic Strategy for Core-Shell Magnetic Nanoparticles," Journal of American Chemistry Society, Vol. 127, No. 46, 2005, pp. 16090-16097. doi: $10.1021 / \mathrm{ja} 053659 \mathrm{j}$

[18] S.-J. Cho, J.-C. Idrobo, J. Olamit, K. Liu, N. D. Browning and S. M. Kauzlarich, "Growth Mechanisms and Oxidation Resistance of Gold-Coated Iron Nanoparticles," Chemistry of Materials, Vol. 17, No. 12, 2005, pp. 3181-3186. doi: $10.1021 / \mathrm{cm} 0500713$

[19] H. Danan, A. Herr and A. J. P. Meyer, "New Determinations of the Saturation Magnetization of Nickel and Iron," Journal of Applied Physics, Vol. 39, No. 2, 1968, pp. 669-670. doi:10.1063/1.2163571 